\title{
Oral Corticosterone Administration Reduces Insulitis but Promotes Insulin Resistance and Hyperglycemia in Male Nonobese Diabetic Mice
}

Susan J. Burke, ${ }^{\star}$ Heidi M. Batdorf, ${ }^{\star \dagger}$ Adrianna E. Eder, ${ }^{\ddagger}$ Michael D. Karlstad, ${ }^{\ddagger}$ David H. Burk, ${ }^{\S}$ Robert C. Noland, Z. Elizabeth Floyd, " and J. Jason Collier*

From the Laboratory of Islet Biology and Inflammation, ${ }^{*}$ the Skeletal Muscle Metabolism Laboratory, ${ }^{\dagger}$ the Cell Biology and Bioimaging Core Facility, ${ }^{\S}$ and the Ubiquitin Biology Laboratory, ${ }^{\circledR}$ Pennington Biomedical Research Center, Baton Rouge, Louisiana; and the Department of Surgery, ${ }^{\ddagger}$ Graduate School of Medicine, University of Tennessee Health Science Center, Knoxville, Tennessee

Accepted for publication

November 23, 2016.

Address correspondence to J. Jason Collier, Ph.D., Pennington Biomedical Research Center, 6400 Perkins Rd, Baton Rouge, LA 70808. E-mail: jason.collier@pbrc.edu.

\begin{abstract}
Steroid-induced diabetes is the most common form of drug-induced hyperglycemia. Therefore, metabolic and immunological alterations associated with chronic oral corticosterone were investigated using male nonobese diabetic mice. Three weeks after corticosterone delivery, there was reduced sensitivity to insulin action measured by insulin tolerance test. Body composition measurements revealed increased fat mass and decreased lean mass. Overt hyperglycemia $(>250 \mathrm{mg} / \mathrm{dL}$ ) manifested 6 weeks after the start of glucocorticoid administration, whereas $100 \%$ of the mice receiving the vehicle control remained normoglycemic. This phenotype was fully reversed during the washout phase and readily reproducible across institutions. Relative to the vehicle control group, mice receiving corticosterone had a significant enhancement in pancreatic insulin-positive area, but a marked decrease in $\mathrm{CD}^{+}$cell infiltration. In addition, there were striking increases in both citrate synthase gene expression and enzymatic activity in skeletal muscle of mice in the corticosterone group relative to vehicle control. Moreover, glycogen synthase expression was greatly enhanced, consistent with elevations in muscle glycogen storage in mice receiving corticosterone. Corticosterone-induced hyperglycemia, insulin resistance, and changes in muscle gene expression were all reversed by the end of the washout phase, indicating that the metabolic alterations were not permanent. Thus, male nonobese diabetic mice allow for translational studies on the metabolic and immunological consequences of glucocorticoidassociated interventions in a mouse model with genetic susceptibility to autoimmune disease. (Am J Pathol 2017, 187: 614-626; http://dx.doi.org/10.1016/j.ajpath.2016.11.009)
\end{abstract}

Type 1 diabetes mellitus (T1D) is an organ-specific autoimmune disease that manifests when circulating insulin levels are reduced because of damaged and dysfunctional pancreatic islet $\beta$-cells. ${ }^{1}$ Although no single trigger has emerged to directly explain the targeted assault on pancreatic islet $\beta$-cells by the host immune system leading to T1D, there are a variety of postulated causes for the increasing incidence of disease. $^{2-5}$ It is well established that innate and adaptive immune pathways are key contributors to the decrements in islet $\beta$-cell mass and function. ${ }^{6-9}$ Proinflammatory cytokines secreted from leukocytes initiate specific signaling cascades, which coordinately alter islet $\beta$-cell transcriptional responses. ${ }^{10,11}$ One major outcome of this genetic reprogramming is the production and release of chemotactic molecules, which regulate leukocytic infiltration into pancreatic tissue. ${ }^{1,12}$ In addition, the proinflammatory cytokines IL- $1 \beta$ and interferon- $\gamma$ also reduce

\footnotetext{
Supported in part by NIH grants P20-GM103528 (J.J.C.) and R01DK103860 (R.C.N.); and in part by a Physicians' Medical Education and Research Foundation (Knoxville, TN) grant (J.J.C. and M.D.K.). This project also used resources provided by the LA CaTS (NIH U54GM104940) center grant and the Pennington Biomedical Research Center Genomics and the Cell Biology and Bioimaging Core Facilities, which are supported in part by COBRE (NIH P20-GM103528) and NORC (NIH P30-DK072476) NIH center grants.
}

Disclosures: None declared. 
insulin secretion, proliferation, and viability through direct actions on $\beta$-cells. ${ }^{12-16}$ Thus, strategies to eliminate or reduce inflammation in pancreatic islets may be ideal approaches for therapeutic intervention to treat autoimmune forms of diabetes.

Glucocorticoids are a major class of lipophilic molecules with powerful anti-inflammatory effects. Endogenously produced glucocorticoids are important steroidal hormones that regulate immune responses, adipocyte differentiation, neurological outcomes, and metabolic homeostasis. ${ }^{17}$ The clinically beneficial impact of glucocorticoids has been recognized for decades and is still used to treat a variety of human diseases that have inflammatory components, including rheumatoid arthritis and inflammatory bowel disease. In addition, early efforts showed a potentially promising utility of glucocorticoid intervention for T1D. ${ }^{18,19}$ However, a host of undesirable metabolic adverse effects often limits the utility of chronic glucocorticoidbased interventions as therapeutic options to treat specific human diseases. ${ }^{20-22}$ One such adverse effect is insulin resistance and the potential for onset of steroid-induced diabetes. $^{23-26}$

In this study, we used male nonobese diabetic (NOD) mice to examine the immunological and metabolic effects associated with chronic glucocorticoid intervention. Male NOD mice display genetic susceptibility for T-lymphocyte infiltration into the pancreatic tissue, but develop diabetes at a much lower frequency than female NOD mice. This reduced incidence of disease makes the male NOD mouse an excellent model in which to investigate specific mechanisms that adversely affect metabolic homeostasis (eg, insulin resistance) while also permitting concomitant evaluation of variables that influence the course of autoimmune disease (eg, immune cell infiltration). Herein, we show that male NOD mice become hyperglycemic after 5 to 6 weeks of oral corticosterone exposure. Changes in insulin sensitivity are apparent before overt hyperglycemia and are completely reversible on removal of the steroid. Major changes in body composition, notably a decrease in lean body mass concomitant with increases in fat mass, are consistent with our observations of insulin resistance and hyperglycemia. On a positive note, corticosterone reduces infiltration of $\mathrm{CD}^{+}$cells into the pancreatic tissue, a phenotype that remains stable after discontinuation of steroid administration. Collectively, our results indicate that male NOD mice are a useful preclinical model system in which to investigate both metabolic and immunological outcomes associated with glucocorticoid receptor activation.

\section{Materials and Methods}

\section{Animals and Reagents}

Male NOD mice were acquired from the Jackson Laboratories (Bar Harbor, ME). Mice between 9 and 11 weeks of age were group housed and allowed to acclimate to the photoperiod (12-hour light/12-hour dark) and temperature conditions $\left(22^{\circ} \mathrm{C} \pm 1{ }^{\circ} \mathrm{C}\right)$ of each animal facility for 7 days. This 1-week acclimation period was standard procedure on animal arrival at each participating institution. During studies at both sites [University of Tennessee (Knoxville, TN) and Pennington Biomedical Research Center (Baton Rouge, LA)], mice were fed Harlan Teklad Diet 8640 (Envigo, Madison, WI) and given access to tap water ad libitum. Randomization into experimental groups was made using fasting blood glucose levels and body weights to ensure these metabolic variables were similar at the onset of the intervention. A baseline blood glucose value was obtained from the tail vein immediately before beginning the drinking water interventions. Corticosterone (27840) was purchased from Sigma-Aldrich (St. Louis, MO) and administered in $1 \%$ ethanol drinking water at $100 \mu \mathrm{g} / \mathrm{mL}$. Briefly, corticosterone was dissolved in ethanol (E7023; Sigma) and diluted with water to make a $1 \%$ ethanol solution. Animals in the vehicle control groups received a $1 \%$ ethanol drinking water solution. Water was changed every 3 to 4 days. Blood glucose levels and body weights were measured once a week throughout the study. Six weeks after corticosterone dosing, mice were taken off of the steroid (and corresponding ethanol vehicle) and switched to standard drinking water for the remainder of the study (denoted as washout phase below). After in vivo measurements were complete, animals were euthanized via carbon dioxide asphyxiation and trunk blood was collected for serum after decapitation. Fat depots, skeletal muscle, and liver were snap frozen in liquid nitrogen for long-term storage at $-80^{\circ} \mathrm{C}$, whereas pancreata were fixed in $10 \%$ neutral-buffered formalin (Sigma) for histological and immunohistochemical analyses. Time-domain nuclear magnetic resonance to measure body composition was performed at Pennington Biomedical Research Center. The ex vivo analyses were also performed at Pennington Biomedical Research Center. All procedures were approved by each respective Institutional Animal Care and Use Committee at the University of Tennessee and Pennington Biomedical Research Center.

\section{Insulin Tolerance Test}

At the beginning of the fourth week of the study ( 3 weeks after initiating the corticosterone regimen), an insulin tolerance test was performed essentially as described. ${ }^{27}$ Briefly, Humulin R insulin (Lilly, Indianapolis, IN) was administered at $0.75 \mathrm{U} / \mathrm{kg}$ body weight via i.p. injection following a 2-hour fast. Blood samples were taken from the tail vein immediately before the injection, as well as at 15 , 30, 60, 90, and 120 minutes after injection. Blood glucose was read with an ACCU-CHEK Aviva PLUS Glucometer (Roche Diagnostics, Indianapolis, IN). Blood glucose levels were plotted against time, and the area under the curve was calculated. 


\section{Islet Histology and Measurements of Serum Insulin}

Our procedures for sectioning, embedding, and measuring insulin-positive area and $\mathrm{CD}^{+}$cell infiltration have been described. ${ }^{28}$ Serum insulin was measured using the Ultrasensitive Mouse Insulin enzyme-linked immunosorbent assay kit (catalog number 10-1249-01) from Mercodia (Uppsala, Sweden), according to their recommended protocol. The IBA1 antibody (catalog number 019-19741) was from Wako (Richmond, VA). Rather than scoring pancreatic insulitis in a binary format, we used the following classification scheme to allow for a semiquantitative analysis: 0 indicates no visible infiltration; 1 , visible periinsulitis with $<10 \%$ of islet occluded; 2 , visible periinsulitis completely encircling the islet but affecting less than half of the islet area; 3 , invasive insulitis, defined as comprising $50 \%$ or more of the islet area being occluded with leukocytic infiltration. Two investigators (D.H.B. and J.J.C.), blinded to the conditions, scored the pancreatic sections. This histology score, given as fractional degree, was calculated by dividing the sum of all individual islet scores by the total number of islets evaluated. For the analysis, two pancreatic sections from each mouse were cut approximately $150 \mu \mathrm{m}$ apart. For each group, between 100 and 350 islets were scored. Each of these values was plotted as a fraction of the total islets counted.

\section{Cell Culture, Luciferase Assays, and Enzyme-Linked Immunosorbent Assay}

Culture and passage of the 832/13 rat insulinoma cell line has been described. ${ }^{29}$ Transient transfection of plasmid vectors into 832/13 cells, luciferase activity measurements, and chemokine ligand (CCL) 2 and CCL20 enzyme-linked immunosorbent assays were performed as described previously. ${ }^{30}$

\section{Total RNA Extraction, cDNA Synthesis, and Real-Time RT-PCR}

Total RNA was isolated from 832/13 cells using TRIReagent solution (Thermo Fisher Scientific, Waltham, MA) and from skeletal muscle using an RNeasy Mini Kit (Qiagen, Hilden, Germany). The rRNA integrity was assessed by $1 \%$ agarose gel. Total RNA was reverse transcribed into cDNA using the iScript cDNA Synthesis kit (Bio-Rad, Hercules, CA). Abundance of specific mRNA transcripts was measured by real-time RT-PCR using a Carbohydrate Metabolism PrimePCR plate (Bio-Rad) and iTaq Universal SYBR Green Supermix (Bio-Rad). The mRNA integrity for each cDNA sample was assessed by the RNA Quality Assay (Bio-Rad), which has been described ${ }^{31}$ (Table 1).

\section{Tissue Protein Isolation and Immunoblotting}

Isolated rectus muscle $(30 \mathrm{mg})$ tissue was homogenized in $300 \mu \mathrm{L}$ T-PER lysis reagent (Thermo Fisher Scientific) supplemented with Halt Protease/Phosphatase Inhibitor Cocktail (Thermo Fisher Scientific). The protein concentration of the lysate was determined using the bicinchoninic acid assay (Thermo Fisher Scientific). Samples were heat denatured, separated on NuPAGE Novex $4 \%$ to $12 \%$ BisTris gels (Thermo Fisher Scientific), transferred to a polyvinylidene difluoride membrane, blocked for 15 minutes in Membrane Blocking Solution (Invitrogen, Carlsbad, CA), and incubated in primary antibody overnight with rotation at $4^{\circ} \mathrm{C}$. The primary antibody was removed, and membranes were washed in tris-buffered saline three times for 5 minutes each time. Membranes were incubated with secondary antibody for 2 hours at room temperature with rotation. Secondary antibody was removed, and membranes were washed in tris-buffered saline three times for 5 minutes each time. Chemiluminescence detection was performed using a ChemiDoc Imaging system (Bio-Rad). Antibodies were from Abcam (Cambridge, UK; Total OXPHOS catalog number ab110413) and Cell Signaling Technology (Danvers, MA; $\beta$-actin catalog number 8457).

\section{Citrate Synthase Activity, Glycogen Assays, and Statistical Analysis}

Glycogen levels were determined from $10 \mathrm{mg}$ of powdered skeletal muscle tissue using the Glycogen Assay kit (Abcam), according to the manufacturer's protocol. Total glycogen content was normalized to total tissue protein. For citrate synthase activity, $10 \mathrm{mg}$ of skeletal muscle tissue was lysed in CelLytic MT Cell Lysis Reagent (Sigma), and enzymatic activity was determined using the Citrate Synthase Assay kit (Sigma), per the manufacturer's guidelines. One-way analysis of variance and $t$-tests were performed using GraphPad Prism software version 6.0 (GraphPad Software, Inc., La Jolla, CA). Specific $P$ values are given in the individual figure legends.

Table 1 Primers Designed Using Primer3Plus Software (Cambridge, MA)

\begin{tabular}{lll}
\hline Gene name & Forward primer & Reverse primer \\
\hline Rs9 & $5^{\prime}$-TCCGGAACAAACGTGAGG-3' & 5'-TCCAGCTTCATCTTGCCC-3' $^{\prime}$ \\
Ccl2 & $5^{\prime}$-ATGCAGTTAATGCCCCACTC-3' & $5^{\prime}-$ TTCCTTATTGGGGTCAGCAC-3' \\
Ccl20 & $5^{\prime}$-GCTTACCTCTGCAGCCAGTC-3' & $5^{\prime}$-CGGATCTTTTCGACTTCAGG-3' \\
\hline
\end{tabular}

Primers for Map1lc3a/LC3 (Mm00458725_g1), MURF1/Trim63 (Mm01185221_m1), and ubiquitin B (Mm01622233_g1) were purchased from Applied Biosystems (Foster City, CA). All other genes were measured using the Carbohydrate Metabolism PrimePCR plate run on the CFX96 real-time system (Bio-Rad, Hercules, CA). 


\section{Results}

\section{Corticosterone Induces Hyperglycemia in Male NOD Mice, Which Is Reversible on Steroid Removal}

This study was designed to investigate the metabolic impact of oral corticosterone delivery in male NOD mice and was conducted at two distinct academic research sites. The twosite approach allowed us to determine the reproducibility of the whole body phenotype across institutions and with distinct investigators. Oral administration of corticosterone has the benefit of reduced handling of animals, therefore eliminating the repeated stress of multiple injections. ${ }^{32}$ Delivery of $100 \mu \mathrm{g} / \mathrm{mL}$ corticosterone occurred via the water supply for 6 weeks, followed by steroid removal (ie, a washout phase) where all mice were given normal drinking water instead of either the ethanol vehicle or corticosterone (Figure 1). The blood glucose results at each site were similar, with significant increases in glucose 5 weeks after beginning the corticosterone regimen (Figure 1, A and B). The combined results from each site are given in Figure 1C. Body weights were also similar between groups at each experimental location (Figure 1, D and E), with the collective data given in Figure $1 \mathrm{~F}$. Thus, corticosterone- induced hyperglycemia, and the subsequent return to normal glucose levels after steroid withdrawal, is clearly a reproducible phenotype across different academic institutions, conducted by separate investigators using a standardized protocol.

\section{Corticosterone Reduces Insulin Sensitivity in Male NOD Mice, a Reversible Phenotype after Removal of Steroid}

The onset of hyperglycemia in response to corticosterone took 5 weeks to develop and was completely reversible on removal of the steroid (Figure 1, A-C). Three weeks after beginning the oral corticosterone regimen, insulin sensitivity was measured by insulin tolerance test (outline of experimental intervention given in Figure 2A). There is a clear ability of insulin to lower blood glucose levels in the vehicle control group (Figure 2B), indicating a normal response to hormone injection. By contrast, this response is markedly blunted in the mice receiving corticosterone (Figure 2B). The area under the curve shows a $22 \%$ difference in mice receiving corticosterone relative to the mice receiving the vehicle control (Figure 2C). Interestingly, 4 weeks after removal of corticosterone (and vehicle),

\section{Site 1}

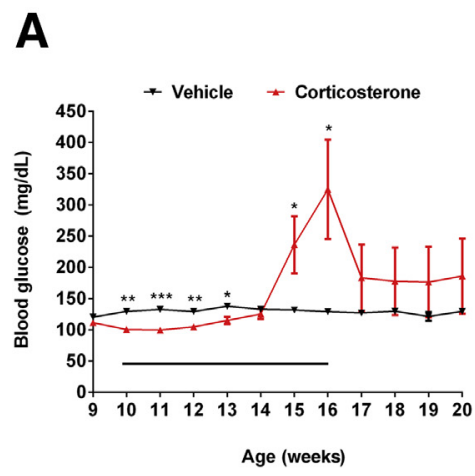

D

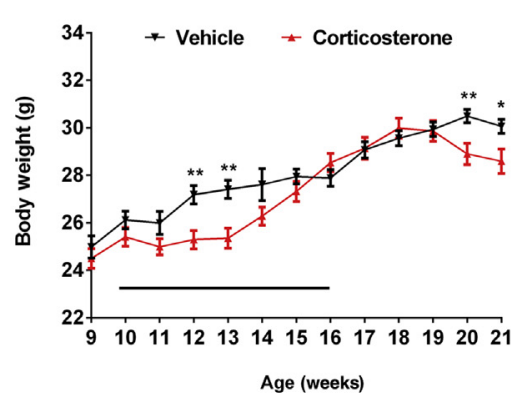

Site 2

B

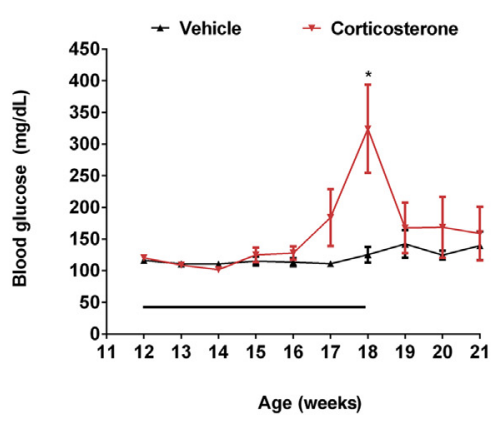

$\mathbf{E}$

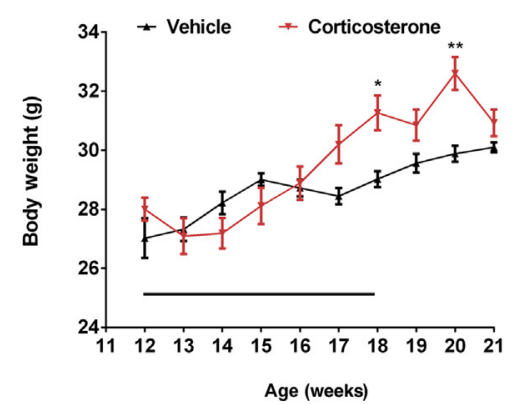

Combined

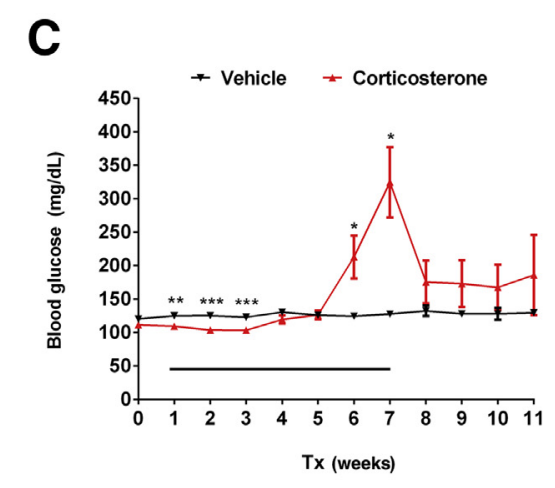

$\mathbf{F}$

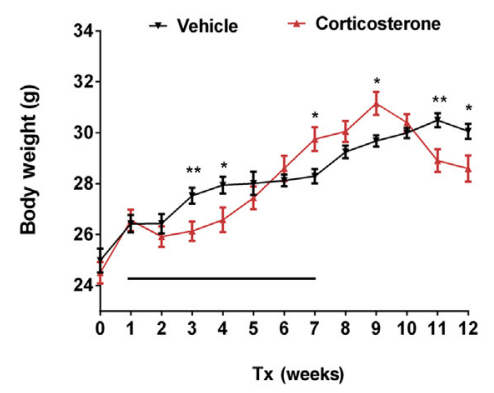

Figure 1 Corticosterone induces hyperglycemia in male NOD mice. Blood glucose (A-C) and body weights (D-F) were measured weekly during both delivery and washout phases. Lines indicate the timeline of vehicle and corticosterone administration. Site 1 indicates Pennington Biomedical Research Center; site 2, University of Tennessee; and the combined graph, the sum of data collected at each site. Data are shown as means \pm SEM. $n=8$ per group $(\mathbf{A}, \mathbf{B}, \mathbf{D}$, and $\mathbf{E}) ; n=16(\mathbf{C}$ and $\mathbf{F})$. ${ }^{*} P<0.05,{ }^{*} P<0.01$, and ${ }^{*} * *<0.001$. Tx, treatment. 
A

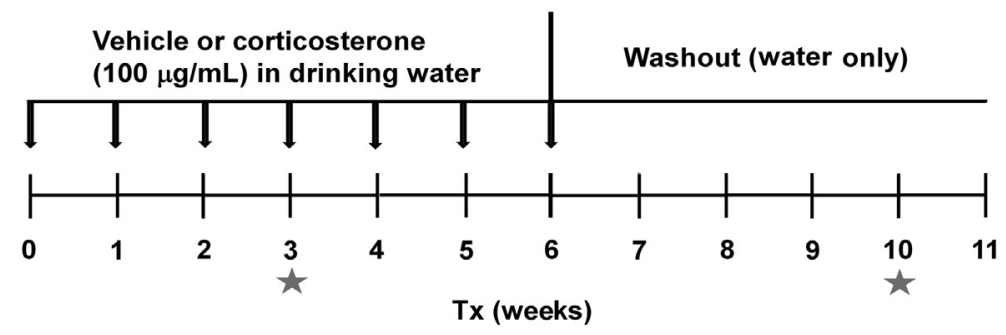

B

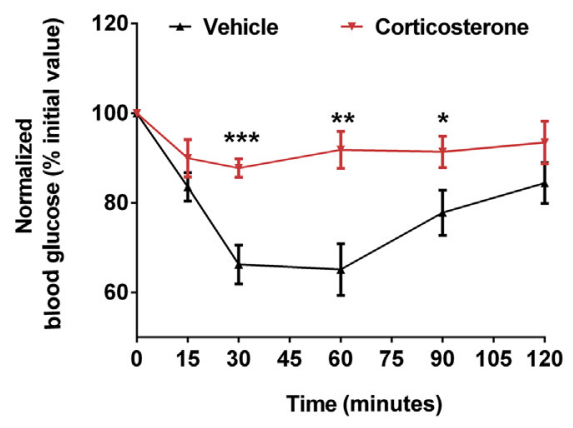

C

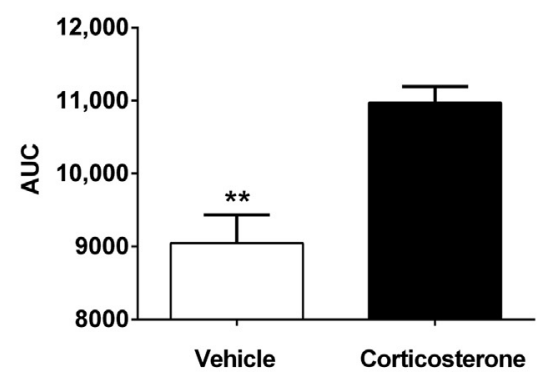

D

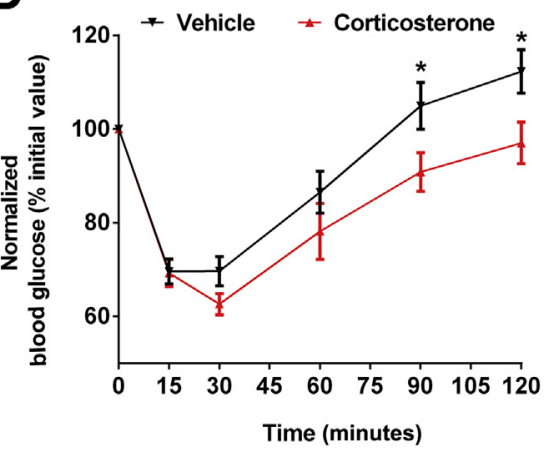

E

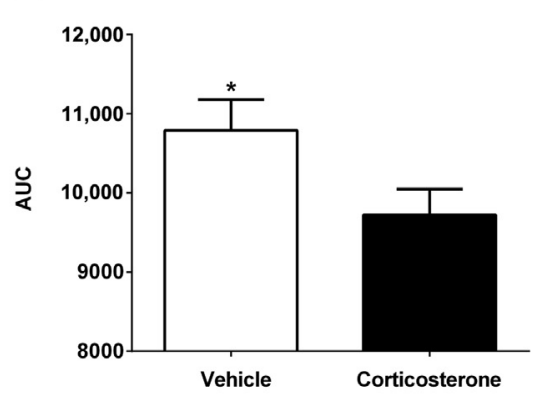

Figure 2 Corticosterone reduces insulin sensitivity in male NOD mice, which is completely reversible after removal of steroid. A: Timeline of vehicle and corticosterone administration [treatment (Tx) phase] and water delivery (washout phase). Insulin tolerance tests (ITTs) were performed at 3 and 10 weeks, as indicated by the gray stars. B-D: Blood glucose levels after bolus injection of insulin are shown after 3 weeks (B) and 10 weeks (D). The area under the curve (AUC) was calculated for ITTs performed at 3 weeks (C) and 10 weeks (E). Data are shown as means \pm SEM (B-E). $n=8$ per group (B-E). ${ }^{*} P<0.05,{ }^{* *} P<0.01$, and ${ }^{* * *} P<0.001$. insulin sensitivity in the mice previously receiving corticosterone returned to normal (Figure 2D). Using the area under the curve calculation, there was a $10 \%$ improvement in the corticosterone group over the vehicle control group, indicating that the mice formerly receiving corticosterone completely recovered from their insulin resistant state by the end of the washout period (Figure 2E).

\section{Corticosterone Stimulates Early and Sustained Alterations in Body Composition that Are Reversible on Steroid Withdrawal}

Oral corticosterone administration promotes early and sustained increases in fat mass (Figure 3A), contributing to the overall escalation in percentage fat accumulation (Figure 3B). By contrast, a striking decrease in lean mass was evident 1 week after mice began the oral corticosterone regimen (Figure 3C). The decrease in percentage lean mass was sustained during the entire course of the corticosterone intervention, but did not get worse over time (Figure 3D).
Fluid mass accumulated much slower (Figure 3, E and F) and tracked most closely with onset of hyperglycemia (Figure 1, A-C). An important observation from this study is the complete reversal of the changes in fat and lean mass after discontinuation of corticosterone. As shown in Figure 3, A and $\mathrm{B}$, fat mass returned to normal on withdrawal of the glucocorticoid. Lean mass was also regained in mice once the steroid was removed (Figure 3, C and D). Moreover, fluid mass decreased concomitantly with the restoration of the euglycemia during the washout phase (Figure 3, E and F). The body composition phenotypes are also consistent with the changes in insulin sensitivity shown in Figure 2.

\section{Corticosterone Increases Expression of the Citrate} Synthase and Glycogen Synthase Genes, Promoting Increases in Enzymatic Activity and Glycogen Storage, Respectively

Using skeletal muscle, changes in several parameters relevant to metabolic homeostasis were investigated. First, 

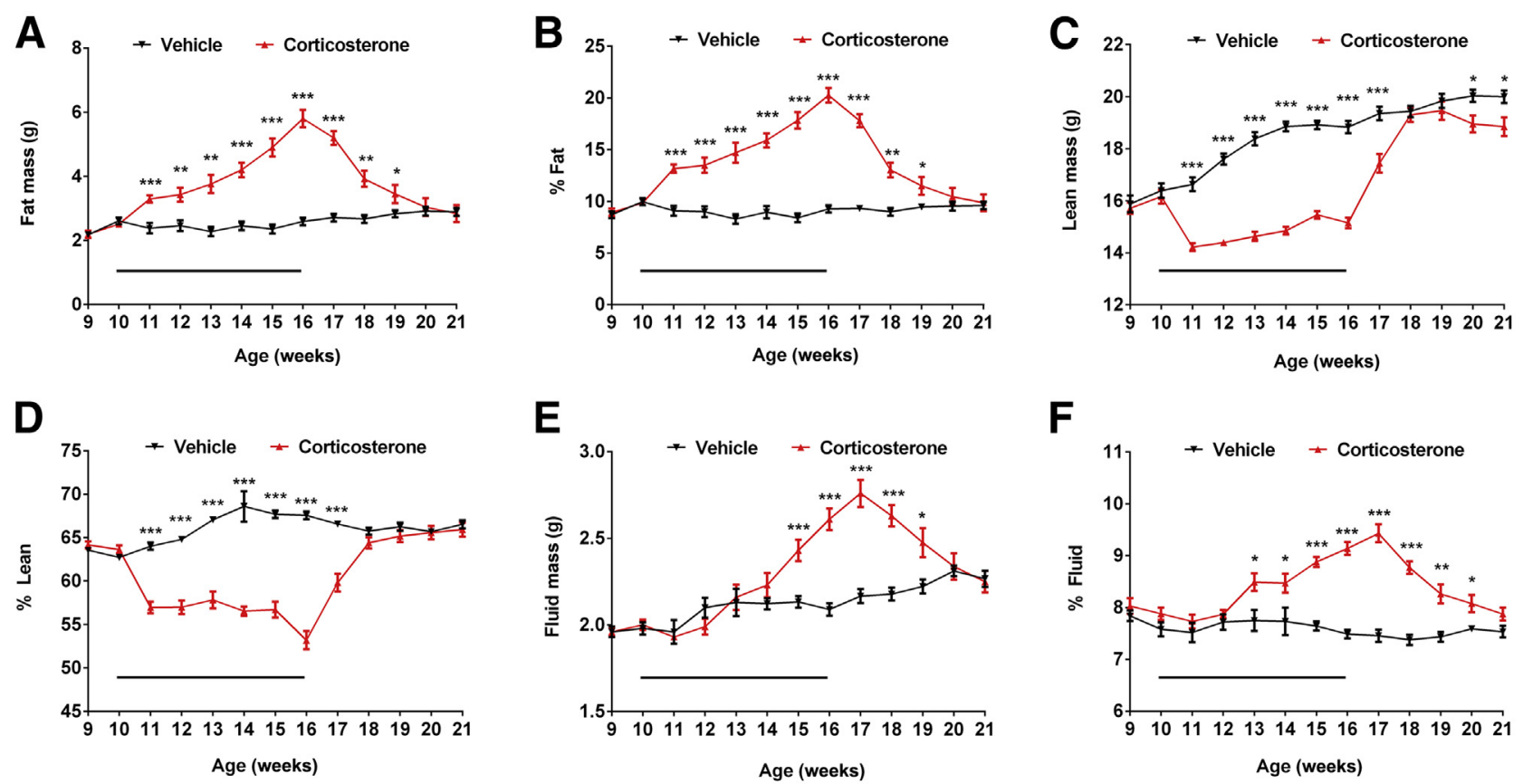

Figure 3 Corticosterone stimulates early and sustained alterations in body composition that are reversible on steroid withdrawal. The solid black bar indicates the timeline of vehicle or corticosterone administration. Fat $(\mathbf{A})$, lean $(\mathbf{C})$, and fluid $(\mathbf{E})$ masses were determined weekly by nuclear magnetic resonance spectroscopy. Fat (B), lean (D) and fluid (F) masses were also calculated as a percentage of body weight. Data are shown as means \pm SEM. $n=8$ per group. ${ }^{*} P<0.05,{ }^{*} P<0.01$, and ${ }^{* * *} P<0.001$.

we found that citrate synthase transcript abundance was markedly up-regulated in skeletal muscle obtained from mice given the corticosterone regimen; expression returned to normal by the end of the washout period (Figure 4A). Citrate synthase enzymatic activity followed a similar pattern as the transcript levels, with elevations during the steroid delivery period, and a return to baseline after removal of the steroid (Figure 4B). Next, we discovered that the gene encoding glycogen synthase was robustly responsive in mice that had received corticosterone but returned to the presteroid state by the end of the washout period (Figure 4C). Glycogen accumulated in skeletal muscle from corticosterone-exposed mice, a phenotype that also reverted to normal on cessation of steroid delivery (Figure 4D). Taken together, alterations in skeletal muscle metabolic homeostasis during chronic glucocorticoid administration were completely reversed on steroid removal.

\section{Corticosterone Promotes the Expression of Genes Regulating Glucose Metabolism and Protein Breakdown, Consistent with Changes in Both Insulin Sensitivity and Decreases in Lean Body Mass}

Because we observed major changes in insulin sensitivity (Figure 2) and glycogen storage (Figure 4D), we next measured genes directly linked with regulation of glucose metabolism. Expression of $P d k 4$, which encodes the enzyme pyruvate dehydrogenase lipoamide kinase isozyme 4 (mitochondrial), was increased nearly 40 -fold in muscle isolated from the mice given corticosterone (Figure 5A). This is consistent with the known regulation of $P d k 4$ by glucocorticoids. ${ }^{33}$ We next examined Pgkl, which encodes the phosphoglycerate kinase, a glycolytic enzyme that catalyzes the reaction 1,3-bisphosphoglycerate + ADP $\rightarrow$ 3-phosphoglycerate and ATP. We found that the expression of the Pgkl gene was reduced by $80 \%$ in muscle isolated from mice in the corticosterone group (Figure 5B). Similar to observations for other genes screened in skeletal muscle, expression of $P g k l$ was restored to normal levels once the corticosterone was removed.

Because of the reduction in insulin tolerance (Figure 2), we investigated the expression of two genes encoding key regulatory enzymes involved in hexosamine production, a metabolic pathway linked with insulin resistance. ${ }^{34}$ The gene encoding glutamine/fructose-6-phosphate amidotransferase (Gfptl), which is considered the rate-controlling enzyme for hexosamine biosynthesis, was elevated 70-fold in muscle from mice in the corticosterone group (Figure 5C). The expression of O-linked- $\beta$-N-acetylglucosamine (O-GlcNAc) transferase $(O g t)$, which produces the enzyme that catalyzes the transfer of O-GlcNAc to serine or threonine residues of proteins, was increased 50-fold in the muscle of mice that had received corticosterone (Figure 5D). Expression of both Gfptl and $O g t$ returned to normal by the end of the steroid washout period (Figure 5, C and D).

We queried the expression of several ubiquitin ligases as a starting point to explain the significant loss in lean body mass in corticosterone-treated mice (Figure 3, C and D). 

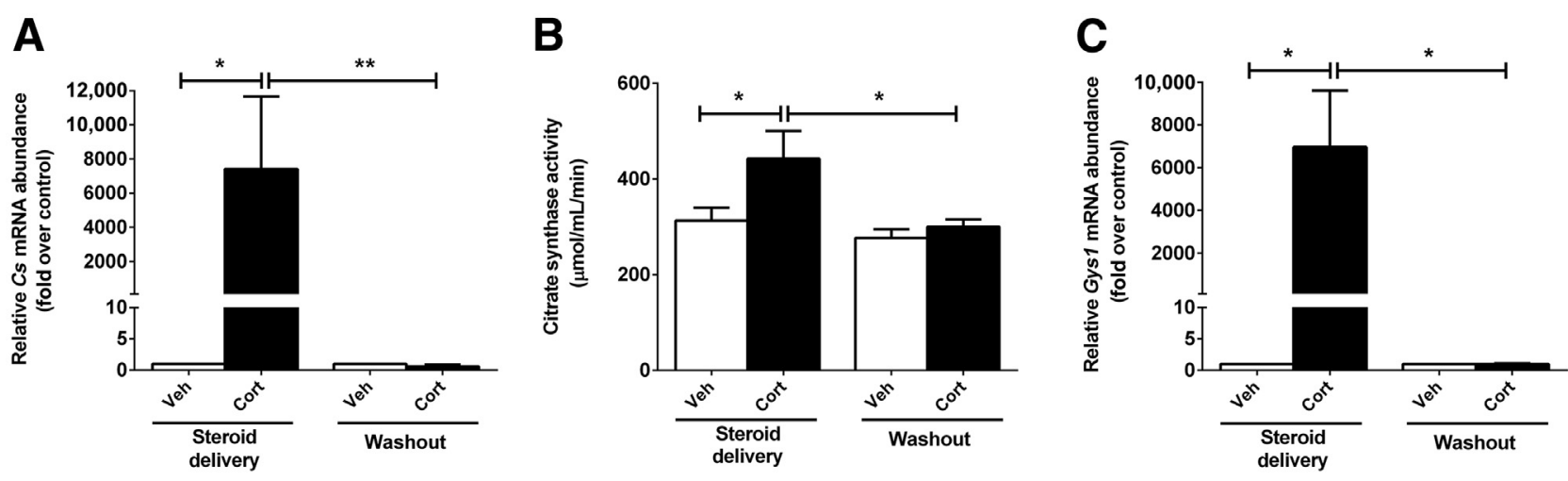

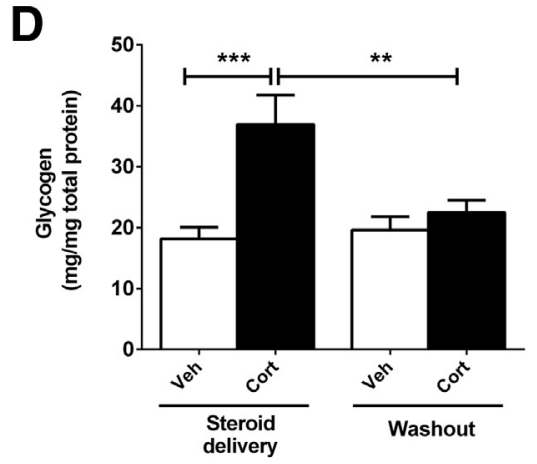

MuRF1, an E3 ubiquitin ligase, was expressed 20-fold higher in muscle from corticosterone-exposed mice relative to vehicle control mice (Figure 5E). Expression of MURF1 returned to normal during the washout period (Figure 5E). In addition, the gene encoding microtubuleassociated protein 1 light chain ( $L C 3)$, a key regulatory ubiquitin-like protein associated with autophagy, was expressed 234-fold over the vehicle control; $L C 3$ expression also reverted to control levels by the end of the washout phase of the study (Figure 5F). The protein abundance of $\beta$-actin, which is decreased in other models of skeletal muscle atrophy, ${ }^{35}$ is also diminished in corticosterone-exposed mice (Supplemental Figure S1). This reduced abundance returns to normal during the washout phase (Supplemental Figure S1). Of significance, the integrity of proteins associated with the electron transport chain is maintained (Supplemental Figure S1), indicating that there is selective, rather than global, protein turnover. Therefore, the skeletal muscle gene expression patterns are consistent with observations of insulin resistance and skeletal muscle wasting shown in Figures 2 and 3 and also with alterations in transcript abundance put forth in Figure 5, E and F.

\section{Corticosterone Enhances Pancreatic Islet Insulin-Positive Area and Islet Fraction, and Is Associated with Marked Increases in Circulating Insulin}

Because pancreatic islets expand during states of insulin resistance, ${ }^{21}$ we measured insulin-positive cell area, indicative of the pancreatic $\beta$-cell population, in response to the corticosterone intervention. Insulin-positive area increased by 2.1-fold in corticosterone-treated mice (Figure 6, A and B). Moreover, there was a marked enhancement in the islet fraction (Figure 6C), a measure of the insulin-positive cell area relative to total pancreatic area. Taken together, these results are consistent with islet $\beta$-cell mass expansion. However, there was no statistically significant increase in either the number of islets per section (Figure 6D) or the glucagon-positive cell area (data not shown). However, circulating insulin was $>25$-fold higher in the corticosterone group when compared with the vehicle control group; this marked elevation in serum insulin completely returned to normal by the end of the washout phase of the study (Figure 6E).

\section{$\mathrm{CD}^{+}$Cell Infiltration Decreases during Corticosterone Intervention and Remained Stable on Steroid Withdrawal}

NOD mice inherently display markedly high levels of lymphocytic infiltration, a key feature of the decrease in islet $\beta$-cell mass that leads to diabetes. ${ }^{28,36}$ The extent of insulitis in the vehicle versus corticosterone groups was examined by histological analysis and given in Figure 7A. We note that 2.7-fold more islets in the corticosterone group were completely free of any visible immune cell association (Figure 7A). By contrast, 8.9-fold more islets in the vehicle group displayed the highest insulitis score possible, indicating a much higher fraction of islet tissue was invasively infiltrated (Figure 7A). After steroid washout, 4.1-fold more 
A

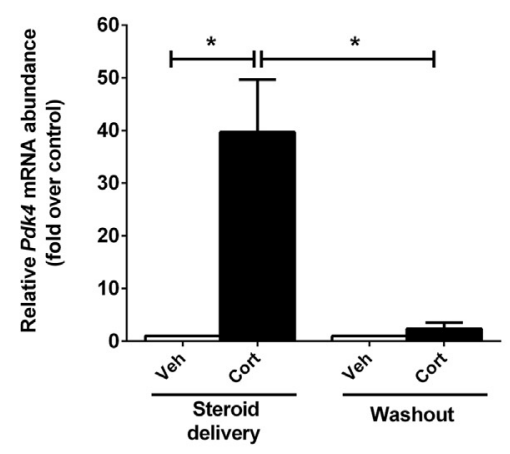

D

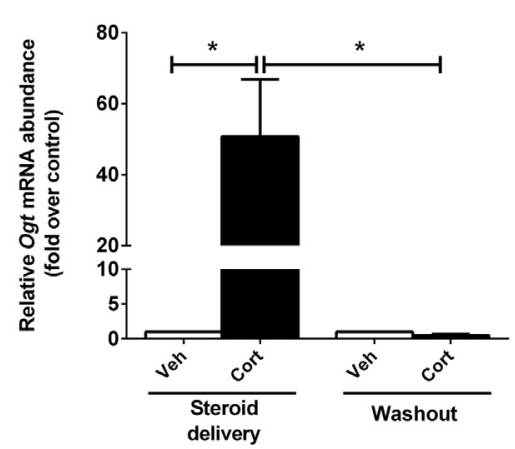

B

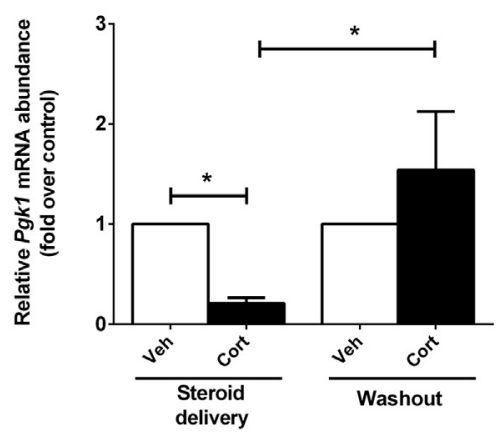

$\mathbf{E}$

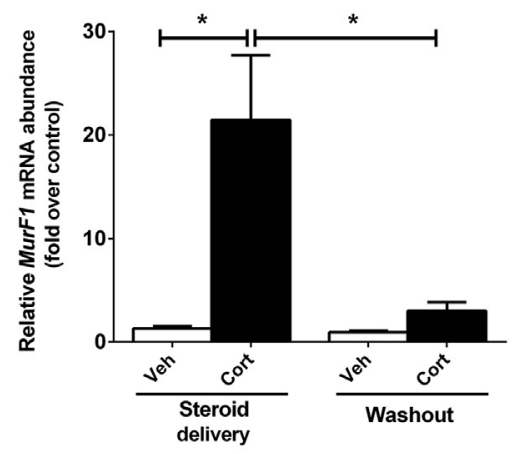

C

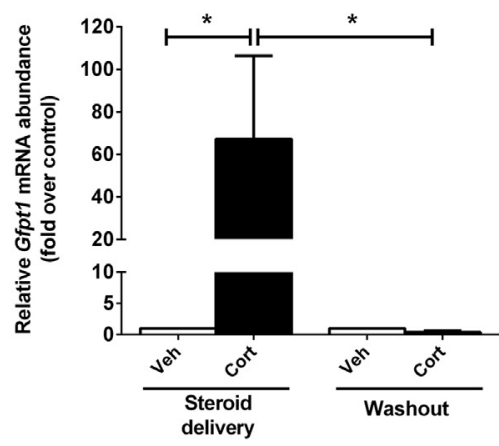

$\mathbf{F}$

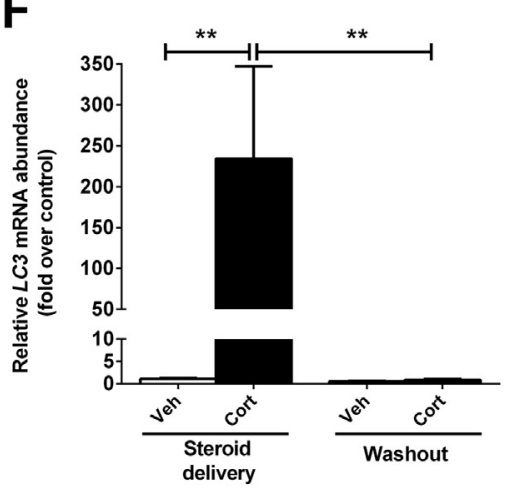

Figure 5 Corticosterone (Cort) promotes the expression of genes regulating glucose metabolism and protein breakdown, consistent with changes in both insulin sensitivity and decreases in lean body mass. Relative Pdk4 (A), Pgk1 (B), Gfpt1 (C), Ogt (D), MuRF1 (E), and LC3 (F) mRNA abundance was determined in rectus muscle from male NOD mice after both delivery and washout phases. Data are shown as means \pm SEM. $n=5$ per group. ${ }^{*} P<0.05,{ }^{*} P<0.01$. Veh, vehicle.

islets in the corticosterone group retained a score of 0 , indicating they were still free of visible immune cell infiltration (Figure 7B). Moreover, we observed that 1.7-fold more islets in the vehicle group received a score of 3 at the conclusion of the washout period, indicting invasive insulitis was more severe in these mice when compared with their counterparts in the corticosterone group (Figure 7B).

We next stained for $\mathrm{CD}^{+}$cells as an indicator of T-lymphocyte entry into the pancreatic tissue. This immunohistological analysis revealed $76 \%$ of islets labeling positive for $\mathrm{CD} 3$ in the vehicle-treated mice (Figure 7C). By contrast, only $44 \%$ of islets were positive in the corticosterone group, with most islets completely free of $\mathrm{CD}^{+}$ immunoreactivity (Figure 7C). These results are congruent with immunosuppressive activity of chronic glucocorticoid administration. After the washout phase, $80 \%$ of the islets in the vehicle group displayed $\mathrm{CD}^{+}$cell infiltration (Figure 7D). However, only 56\% of the islets in the corticosterone group were positive for $\mathrm{T}$ lymphocytes. We also noticed a reduction in active macrophages during corticosterone administration (Supplemental Figure S2), which was also apparent after the washout was complete (Supplemental Figure S3).

To explain the corticosterone-mediated decrease in $\mathrm{T}$ lymphocytes (marked by CD3) and active macrophages (marked by IBA1), we investigated the direct actions of the steroid on cultured rat $\beta$-cells. We found that corticosterone promoted robust glucocorticoid receptor activation (Supplemental Figure S4A). The map kinase phosphatase 1 (alias DUSP1) was also rapidly induced by corticosterone, a phenotype reproduced by the synthetic glucocorticoid dexamethasone (Supplemental Figure S4B). In addition, the IL-1 $\beta$-mediated expression of the chemokine CCL2 was decreased by cellular exposure to corticosterone (Supplemental Figure S4C). CCL2 secretion was also reduced in the presence of the steroid (Supplemental Figure S4D). The CCL20 gene is even more strikingly up-regulated by IL-1 $\beta$, with marked reductions in this response when corticosterone is present (Supplemental Figure S4E). Secretion of CCL20 is also significantly diminished by corticosterone (Supplemental Figure S4F). Taken together, the decrease in chemokine production from pancreatic $\beta$-cells is consistent with a reduction in the number of islets infiltrated by host immune cells.

\section{Discussion}

Prevention and reversal of T1D are major goals of both basic and clinical research endeavors. A variety of strategies targeting inflammatory responses have revealed key roles 
A
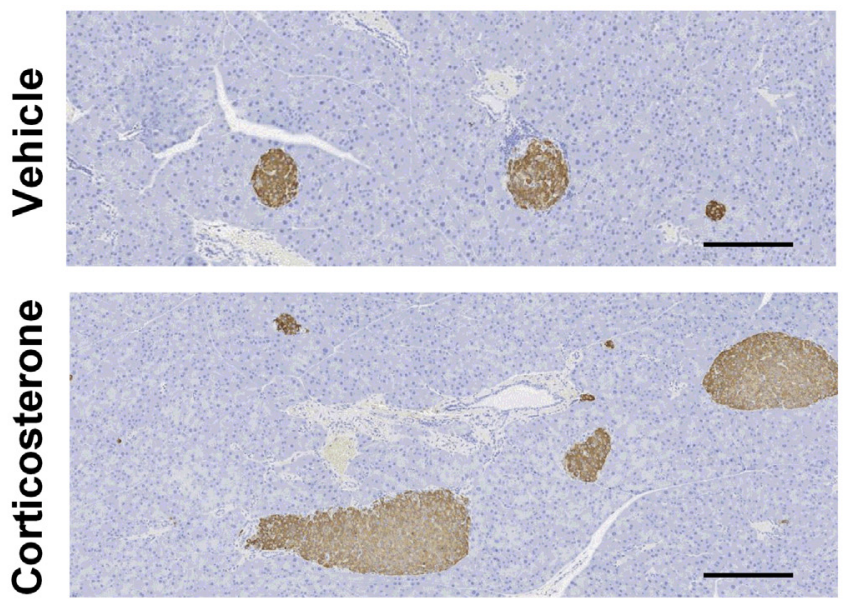

B

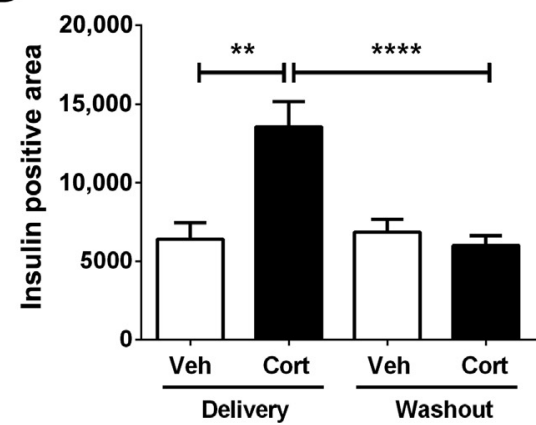

D

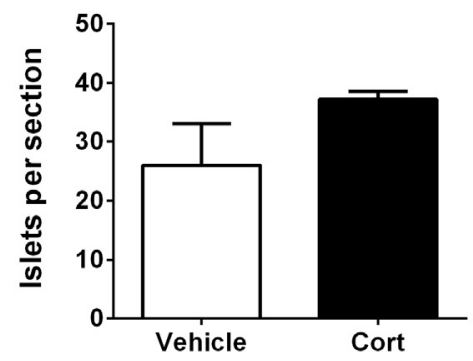

C

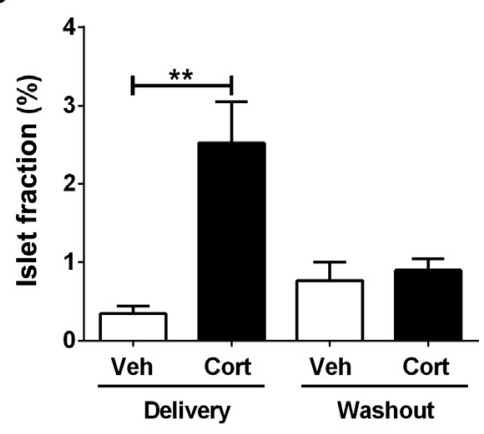

E

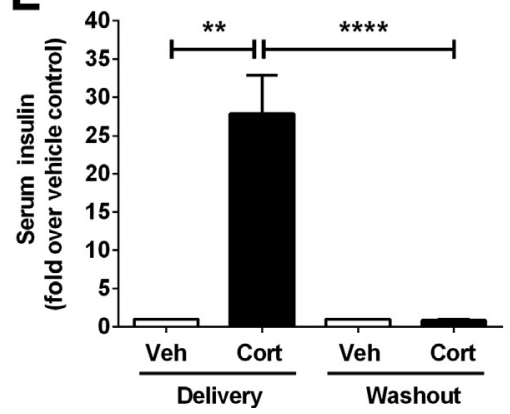

Figure 6 Corticosterone (Cort) enhances pancreatic islet insulin-positive area and is associated with marked increases in circulating insulin. Male NOD mice received either vehicle (Veh) or corticosterone $(100 \mu \mathrm{g} / \mathrm{mL})$ for 6 weeks, followed by steroid withdrawal (washout). Pancreatic islet insulin-positive area was evaluated by immunohistochemical analysis. A: The larger pancreatic islets in the glucocorticoid-treated mice. Insulinpositive area (B), islet fraction (C), and islet per section (D) were quantified using five mice per group. E: Serum insulin was measured by enzymelinked immunosorbent assay with eight mice per group. Data are shown as means \pm SEM $(\mathbf{B}-\mathbf{E})$. ${ }^{* *} P<0.01,{ }^{* * * *} P<0.0001$. Scale bar $=100 \mu \mathrm{m}$ (A). Original magnification, $\times 40(A)$. for specific signaling pathways that participate in the disease course. ${ }^{7,37-39}$ Therefore, understanding the mechanisms associated with anti-inflammatory approaches, such as glucocorticoid receptor activation, offers much promise for controlling diseases with autoimmune and autoinflammatory components. Because the therapeutic use of glucocorticoids is often associated with adverse metabolic phenotypes, including steroid-induced hyperglycemia, ${ }^{23,40,41}$ separating metabolic effects from immunological outcomes requires further investigation. In addition, chronic stress responses, including elevations in circulating glucocorticoids, correlate significantly with insulin resistance, glucose intolerance, and blood glucose levels in humans. ${ }^{42}$ Therefore, we used the male NOD mouse to investigate specific metabolic and immunological parameters associated with chronic oral administration of glucocorticoid.
Using the insulin tolerance test, we found that the ability of injected insulin to lower blood glucose levels was vastly reduced in mice receiving corticosterone. This decrease in insulin action occurred before the onset of overt hyperglycemia (Figures 1 and 2). These results can be explained in part by the striking changes in body composition. Corticosterone administration resulted in marked elevations in fat mass, with concomitant decreases in lean mass (Figure 3). The reciprocal alterations in body composition induced by oral corticosterone delivery are consistent with the development of insulin resistance (Figure 8). In addition, on steroid withdrawal, the changes in body composition were reversed (ie, fat mass decreased and lean mass increased) with corresponding improvements in whole body insulin sensitivity (Figure 2). These findings are consistent with observations in human subjects exposed to 
A

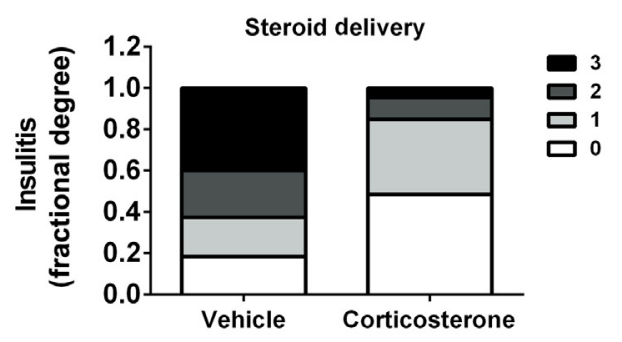

C
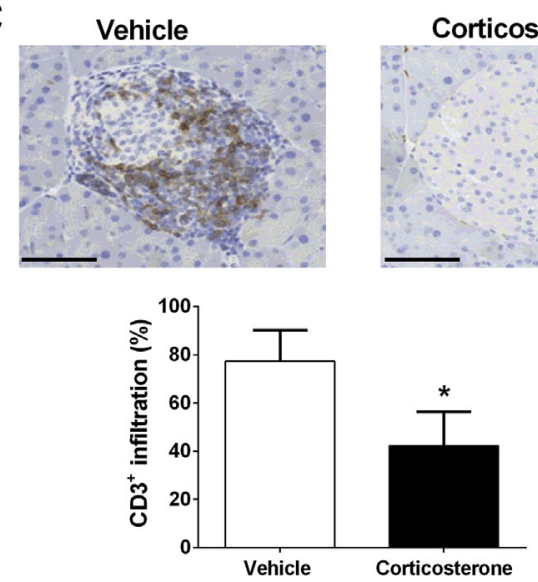

B

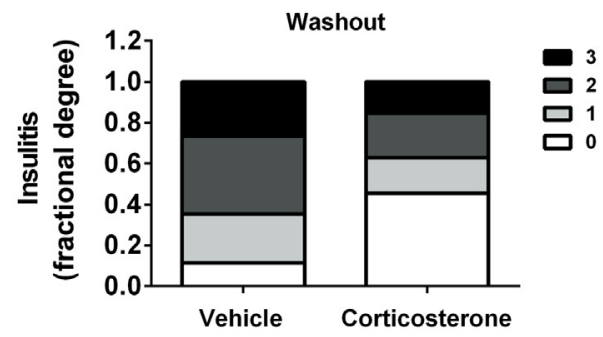

D
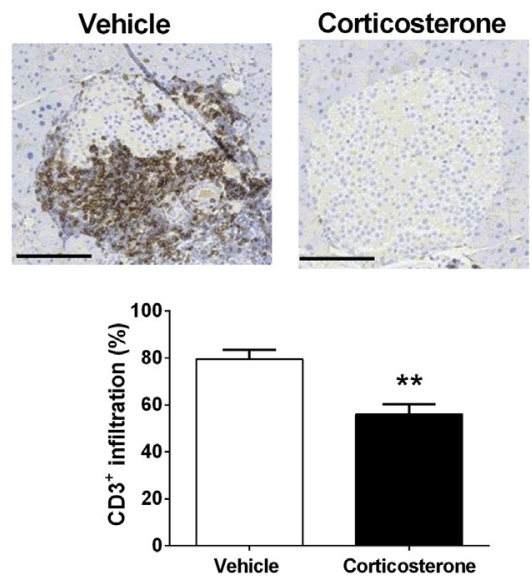

Figure 7 Corticosterone reduces total insulitis and $\mathrm{CD}^{+}$cell infiltration. Male NOD mice were given corticosterone or ethanol vehicle in the drinking water for 6 weeks, followed by a 1-month washout period. A: Insulitis was quantified at the end of the 6-week steroid delivery arm of the study. B: The insulitis score was determined after the 1-month washout phase. Photomicrographs of $\mathrm{CD}^{+}$staining in pancreatic tissue at the end of the 6 -week glucocorticoid intervention (C) and 1 month after the steroid removal (D). Islets of similar size were chosen for comparison. The bar graphs in $\mathbf{C}$ and $\mathbf{D}$ show quantification of islets from four to eight mice per group. ${ }^{*} P<0.05,{ }^{*} P<0.01$. Scale bar $=50 \mu \mathrm{m}$ (C and D). Original magnification, $\times 40$ (C and D).

glucocorticoids $^{22,43}$ and with recent opinion on nuclear hormone receptor control of insulin resistance. ${ }^{44}$

Because skeletal muscle mass contributes significantly to whole body glucose utilization, we examined a variety of genes associated with glucose metabolism and tissue atrophy. Pdk4, a known glucocorticoid responsive gene, was markedly elevated in the corticosterone group (Figure 5A). The increased expression of $P d k 4$ suggests a decrease in glucose oxidation, thereby promoting enhanced glucose storage as glycogen. This was confirmed by analysis of muscle glycogen content (Figure 4D). Also, glycogen synthase is up-regulated during nutrient deprivation and interacts with LC3 at the autophagosome to increase glycogen degradation (glycogen autophagy) as an energy source. This may help to explain why the expression of glycogen synthase is markedly elevated relative to the amount of glycogen detected in skeletal muscle (Figure 4, A and B). In addition, genes encoding key enzymes involved in hexosamine biosynthesis (Gfptl) and transfer of associated substrates $(O g t)$ were also elevated during corticosterone administration, but returned to normal levels after the washout period (Figure 5). These results are congruent with earlier transgenic mouse and glucosamine infusion studies showing that elevations in hexosamine levels promote insulin resistance ${ }^{45,46}$ and further suggest that glucocorticoid- mediated reductions in insulin sensitivity may be associated with increases in cellular hexosamine production.

We also observed increases in the expression of MuRF1 and $L C 3$, genes involved in ubiquitin-mediated protein degradation and autophagy, respectively (Figure 5, E and

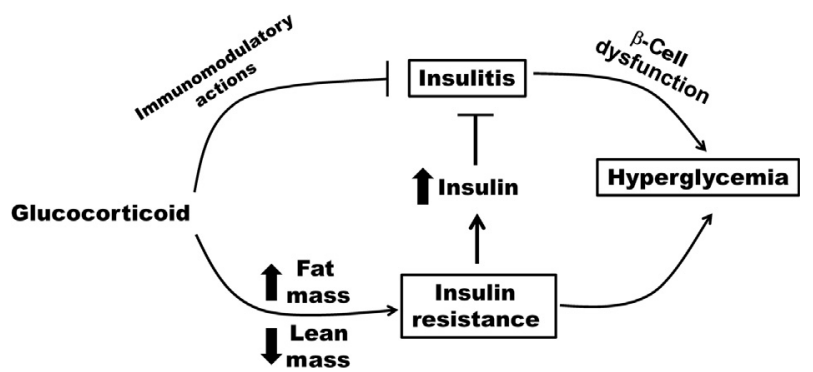

Figure 8 Glucocorticoids display robust immunomodulatory actions, but promote changes in body composition that correlate with insulin resistance, hyperinsulinemia, and eventual onset of hyperglycemia. Oral glucocorticoid delivery reduces leukocytic infiltration into pancreatic tissue. However, chronic administration of the steroid increases total fat mass, reduces whole body lean mass, and promotes insulin resistance. Insulin resistance is linked to hyperinsulinemia and increases in islet $\beta$-cell mass, whereas elevations in circulating insulin are reported to suppress insulitis (see Discussion for details and accompanying references). Severe insulin resistance, often coupled with $\beta$-cell dysfunction, prompts the eventual onset of hyperglycemia. Many of the phenotypes shown in this schematic also occur in humans and also are reversible on cessation of steroid administration. 
F). These findings help to explain the losses in lean mass during the course of corticosterone administration (Figure 3, $\mathrm{C}$ and $\mathrm{D})$. In addition to promoting skeletal muscle atrophy, glucocorticoids also prevent protein synthesis in muscle. ${ }^{47}$ Furthermore, glucocorticoids are known to promote adipogenesis, ${ }^{48}$ consistent with the increases in fat mass observed in the present study. Taken together, these data provide at least a partial explanation for the changes in body composition observed during oral corticosterone delivery and also after discontinuation of the steroid hormone regimen.

An interesting observation between our studies and those conducted using C57BL/6 mice is the difference in time to develop hyperglycemia. Appearance of elevated blood glucose levels was reported to occur in the first week in a study using the C57BL/6 strain, ${ }^{49}$ but is slower to develop in the NOD mouse (Figure 1). At the present time, we do not know why the NOD strain is more resistant to hyperglycemia than the C57BL/6 strain in response to oral delivery of corticosterone. The most likely explanation is that NOD mice are less prone to insulin resistance induced by glucocorticoids than are mice on the C57BL/6 background. This interpretation is consistent with recent studies showing that the NOD strain is less sensitive to high-fat diet-induced weight gain and associated insulin resistance when compared with C57BL/6 mice. ${ }^{50}$ Moreover, the observed distinctions in separate strains of mice parallel observations reported in human studies, with AfricanAmerican individuals displaying enhanced sensitivity to dexamethasone when compared with white Americans. ${ }^{51}$ Polymorphisms that alter expression of the glucocorticoid receptor gene or responses to corticosteroid ligands could also influence the severity of metabolic outcomes. ${ }^{52}$

We further found that corticosterone activates the glucocorticoid receptor and suppresses chemokine production from cultured $\beta$-cells (Supplemental Figure S4). Chemokines (ie, chemotactic cytokines) are responsible for recruiting particular populations of immune cells through activation of their specific cell surface receptors. ${ }^{53}$ Thus, one potential approach to reduce immune cell infiltration into the pancreatic islets is to reduce the synthesis and secretion of chemoattractant molecules, such as CCL2 and CCL20. These two chemokines recruit macrophages and $\mathrm{T}$ lymphocytes, ${ }^{11,54-56}$ which are leukocytes implicated in $\beta$-cell death during development of T1D. ${ }^{57}$ Therapeutic benefit, including reduced insulitis, is achieved after injection of a synthetic $\mathrm{p} 38$ mitogen-activated protein kinase inhibitor into NOD mice. ${ }^{58}$ Our results showing up-regulation of map kinase phosphatase 1 in $\beta$-cells ${ }^{59}$ (Supplemental Figure S4B), which restricts signaling through the p38 mitogen-activated protein kinase pathway, ${ }^{59}$ are consistent with the observed reduction in insulitis after corticosterone delivery (Figure 7 and Supplemental Figure S4). Our findings thus suggest a prospective mechanism for reduced insulitis in the current corticosterone administration model, which is a reduction in $\beta$-cell-derived chemokine production and secretion.
Thus, down-regulation of immune cell modulatory chemokines is a plausible explanation for the reduced insulitis in our current study. Additional anti-inflammatory actions of glucocorticoid receptor activation are also postulated to be part of the immunomodulatory component of the corticosterone phenotype.

The establishment and characterization of diverse mouse models of glucocorticoid delivery provide unique opportunities in which to investigate the effects of novel glucocorticoid receptor agonist molecules. For example, the use of azaxanthene, ${ }^{60}$ arylindazole,${ }^{61}$ mercaptosteroid, ${ }^{62}$ or other molecules designed to target inflammation, could potentially be novel therapeutic interventions for autoimmune and autoinflammatory diseases, including T1D. Our observations showing that corticosterone has lasting effects on insulitis 4 weeks after withdrawal (Figure 7) are analogous to the reported effects of prednisone in human T1D studies. ${ }^{18,19}$ Indeed, in human subjects with new-onset T1D who received 8 weeks of prednisone treatment, antibodies against insulin were significantly reduced months after steroid withdrawal. ${ }^{18}$ Thus, it is entirely conceivable that activation of the glucocorticoid receptor has long-lasting immunomodulatory and immunogenetic effects that have been underappreciated and warrant further investigation.

On a final note, the hyperinsulinemia induced by glucocorticoids (Figure 6E) may also have been a factor in controlling the degree of insulitis in our study (Figure 8). This idea is consistent with observations put forth in previous work, where aggressive insulin therapy reduced insulitis and vastly decreased the onset of autoimmune diabetes in NOD mice. ${ }^{63}$ Similar experiments conducted using the BB rat, another rodent model of diabetes because of autoimmune destruction of islet $\beta$-cells, also revealed protective effects of exogenously administered insulin. ${ }^{64}$ Therefore, it is conceivable that a combination therapy, involving insulin, a novel synthetic glucocorticoid receptor modulating compound, or both strategies might be beneficial as direct or adjuvant therapeutic considerations in the quest to prevent and treat T1D. Future studies will be designed to test such possibilities.

\section{Acknowledgments}

We thank Gail Effler-Braymer and Jacob Simon for technical assistance.

\section{Supplemental Data}

Supplemental material for this article can be found at http://dx.doi.org/10.1016/j.ajpath.2016.11.009.

\section{References}

1. Atkinson MA, Eisenbarth GS, Michels AW: Type 1 diabetes. Lancet 2014, 383:69-82 
2. Wasserfall C, Nead K, Mathews C, Atkinson MA: The threshold hypothesis: solving the equation of nurture vs nature in type 1 diabetes. Diabetologia 2011, 54:2232-2236

3. Fourlanos S, Harrison LC, Colman PG: The accelerator hypothesis and increasing incidence of type 1 diabetes. Curr Opin Endocrinol Diabetes Obes 2008, 15:321-325

4. Dahlquist G: Can we slow the rising incidence of childhood-onset autoimmune diabetes? The overload hypothesis. Diabetologia 2006, 49:20-24

5. Wilkin TJ: The accelerator hypothesis: a review of the evidence for insulin resistance as the basis for type I as well as type II diabetes. Int J Obes (Lond) 2009, 33:716-726

6. Diana J, Simoni Y, Furio L, Beaudoin L, Agerberth B, Barrat F, Lehuen A: Crosstalk between neutrophils, B-1a cells and plasmacytoid dendritic cells initiates autoimmune diabetes. Nat Med 2013, 19: $65-73$

7. Wallberg M, Cooke A: Immune mechanisms in type 1 diabetes. Trends Immunol 2013, 34:583-591

8. Burke SJ, Collier JJ: Insulitis and diabetes: a perspective on islet inflammation. Immunome Res 2014, 10. Special Issue: Cytokine Biology

9. Lehuen A, Diana J, Zaccone P, Cooke A: Immune cell crosstalk in type 1 diabetes. Nat Rev Immunol 2010, 10:501-513

10. Lopes M, Kutlu B, Miani M, Bang-Berthelsen CH, Storling J, Pociot F, Goodman N, Hood L, Welsh N, Bontempi G, Eizirik DL: Temporal profiling of cytokine-induced genes in pancreatic beta-cells by meta-analysis and network inference. Genomics 2014, 103: 264-275

11. Burke SJ, Collier JJ: Transcriptional regulation of chemokine genes: a link to pancreatic islet inflammation? Biomolecules 2015, 5: 1020-1034

12. Collier JJ, Fueger PT, Hohmeier HE, Newgard CB: Pro- and antiapoptotic proteins regulate apoptosis but do not protect against cytokine-mediated cytotoxicity in rat islets and beta-cell lines. Diabetes 2006, 55:1398-1406

13. Rehman KK, Bertera S, Bottino R, Balamurugan AN, Mai JC, Mi Z, Trucco M, Robbins PD: Protection of islets by in situ peptidemediated transduction of the Ikappa B kinase inhibitor Nemobinding domain peptide. J Biol Chem 2003, 278:9862-9868

14. Steer SA, Scarim AL, Chambers KT, Corbett JA: Interleukin-1 stimulates beta-cell necrosis and release of the immunological adjuvant HMGB1. PLoS Med 2006, 3:e17

15. Collier JJ, Burke SJ, Eisenhauer ME, Lu D, Sapp RC, Frydman CJ, Campagna SR: Pancreatic beta-cell death in response to proinflammatory cytokines is distinct from genuine apoptosis. PLoS One 2011, 6:e22485

16. Burke SJ, Stadler K, Lu D, Gleason E, Han A, Donohoe DR, Rogers RC, Hermann GE, Karlstad MD, Collier JJ: IL-1beta reciprocally regulates chemokine and insulin secretion in pancreatic betacells via NF-kappaB. Am J Physiol Endocrinol Metab 2015, 309: E715-E726

17. Kadmiel M, Cidlowski JA: Glucocorticoid receptor signaling in health and disease. Trends Pharmacol Sci 2013, 34:518-530

18. Goday A, Pujol-Borrell R, Fernandez J, Casamitjana R, Rios M, Vilardell E, Gomis R: Effects of a short prednisone regime at clinical onset of type 1 diabetes. Diabetes Res Clin Pract 1993, 20: 39-46

19. Secchi A, Pastore MR, Sergi A, Pontiroli AE, Pozza G: Prednisone administration in recent onset type I diabetes. J Autoimmun 1990, 3: $593-600$

20. Kauh EA, Mixson LA, Shankar S, McCarthy J, Maridakis V, Morrow L, Heinemann L, Ruddy MK, Herman GA, Kelley DE, Hompesch M: Short-term metabolic effects of prednisone administration in healthy subjects. Diabetes Obes Metab 2011, 13: $1001-1007$

21. Burke SJ, Karlstad MD, Collier JJ: Pancreatic islet responses to metabolic trauma. Shock 2016, 46:230-238
22. Beard JC, Halter JB, Best JD, Pfeifer MA, Porte D Jr: Dexamethasone-induced insulin resistance enhances $\mathrm{B}$ cell responsiveness to glucose level in normal men. Am J Physiol 1984, 247:E592-E596

23. Tamez-Perez HE, Quintanilla-Flores DL, Rodriguez-Gutierrez R, Gonzalez-Gonzalez JG, Tamez-Pena AL: Steroid hyperglycemia: prevalence, early detection and therapeutic recommendations: a narrative review. World J Diabetes 2015, 6:1073-1081

24. Rafacho A, Ortsater H, Nadal A, Quesada I: Glucocorticoid treatment and endocrine pancreas function: implications for glucose homeostasis, insulin resistance and diabetes. J Endocrinol 2014, 223:R49-R62

25. Perez A, Jansen-Chaparro S, Saigi I, Bernal-Lopez MR, Minambres I, Gomez-Huelgas R: Glucocorticoid-induced hyperglycemia. J Diabetes 2014, 6:9-20

26. Kwon S, Hermayer KL: Glucocorticoid-induced hyperglycemia. Am J Med Sci 2013, 345:274-277

27. Wicks SE, Vandanmagsar B, Haynie KR, Fuller SE, Warfel JD, Stephens JM, Wang M, Han X, Zhang J, Noland RC, Mynatt RL: Impaired mitochondrial fat oxidation induces adaptive remodeling of muscle metabolism. Proc Natl Acad Sci U S A 2015, 112: E3300-E3309

28. Burke SJ, Karlstad MD, Eder AE, Regal KM, Lu D, Burk DH, Collier JJ: Pancreatic beta-cell production of CXCR3 ligands precedes diabetes onset. Biofactors 2016, 42(6):703-715

29. Hohmeier HE, Mulder H, Chen G, Henkel-Rieger R, Prentki M, Newgard CB: Isolation of INS-1-derived cell lines with robust ATPsensitive $\mathrm{K}+$ channel-dependent and -independent glucose-stimulated insulin secretion. Diabetes 2000, 49:424-430

30. Burke SJ, Karlstad MD, Regal KM, Sparer TE, Lu D, Elks CM, Grant RW, Stephens JM, Burk DH, Collier JJ: CCL20 is elevated during obesity and differentially regulated by NF-kappaB subunits in pancreatic beta-cells. Biochim Biophys Acta 2015, 1849:637-652

31. Vermeulen J, De Preter K, Lefever S, Nuytens J, De Vloed F, Derveaux S, Hellemans J, Speleman F, Vandesompele J: Measurable impact of RNA quality on gene expression results from quantitative PCR. Nucleic Acids Res 2011, 39:e63

32. Karatsoreos IN, Bhagat SM, Bowles NP, Weil ZM, Pfaff DW, McEwen BS: Endocrine and physiological changes in response to chronic corticosterone: a potential model of the metabolic syndrome in mouse. Endocrinology 2010, 151:2117-2127

33. Connaughton S, Chowdhury F, Attia RR, Song S, Zhang Y, Elam MB, Cook GA, Park EA: Regulation of pyruvate dehydrogenase kinase isoform 4 (PDK4) gene expression by glucocorticoids and insulin. Mol Cell Endocrinol 2010, 315:159-167

34. McClain DA, Crook ED: Hexosamines and insulin resistance. Diabetes 1996, 45:1003-1009

35. Rossoll W, Jablonka S, Andreassi C, Kroning AK, Karle K, Monani UR, Sendtner M: Smn, the spinal muscular atrophydetermining gene product, modulates axon growth and localization of beta-actin mRNA in growth cones of motoneurons. J Cell Biol 2003, 163:801-812

36. Jayasimhan A, Mansour KP, Slattery RM: Advances in our understanding of the pathophysiology of type 1 diabetes: lessons from the NOD mouse. Clin Sci (Lond) 2014, 126:1-18

37. Mandrup-Poulsen T, Pickersgill L, Donath MY: Blockade of interleukin 1 in type 1 diabetes mellitus. Nat Rev Endocrinol 2010, 6:158-166

38. Grewal IS, Flavell RA: New insights into insulin dependent diabetes mellitus from studies with transgenic mouse models. Lab Invest 1997, $76: 3-10$

39. Hu C, Ding H, Li Y, Pearson JA, Zhang X, Flavell RA, Wong FS, Wen L: NLRP3 deficiency protects from type 1 diabetes through the regulation of chemotaxis into the pancreatic islets. Proc Natl Acad Sci U S A 2015, 112:11318-11323

40. van Raalte DH, Diamant M: Steroid diabetes: from mechanism to treatment? Neth J Med 2014, 72:62-72

41. Hwang JL, Weiss RE: Steroid-induced diabetes: a clinical and molecular approach to understanding and treatment. Diabetes Metab Res Rev 2014, 30:96-102 
42. Siddiqui A, Madhu SV, Sharma SB, Desai NG: Endocrine stress responses and risk of type 2 diabetes mellitus. Stress 2015, 18:498-506

43. Olefsky JM, Kimmerling G: Effects of glucocorticoids on carbohydrate metabolism. Am J Med Sci 1976, 271:202-210

44. Kang S, Tsai LT, Rosen ED: Nuclear mechanisms of insulin resistance. Trends Cell Biol 2016, 26:341-351

45. Hebert LF Jr, Daniels MC, Zhou J, Crook ED, Turner RL, Simmons ST, Neidigh JL, Zhu JS, Baron AD, McClain DA: Overexpression of glutamine:fructose-6-phosphate amidotransferase in transgenic mice leads to insulin resistance. J Clin Invest 1996, 98: 930-936

46. Hawkins M, Barzilai N, Liu R, Hu M, Chen W, Rossetti L: Role of the glucosamine pathway in fat-induced insulin resistance. J Clin Invest 1997, 99:2173-2182

47. Long W, Wei L, Barrett EJ: Dexamethasone inhibits the stimulation of muscle protein synthesis and PHAS-I and p70 S6-kinase phosphorylation. Am J Physiol Endocrinol Metab 2001, 280: E570-E575

48. Pantoja C, Huff JT, Yamamoto KR: Glucocorticoid signaling defines a novel commitment state during adipogenesis in vitro. Mol Biol Cell 2008, 19:4032-4041

49. Fransson L, Franzen S, Rosengren V, Wolbert P, Sjoholm A, Ortsater H: beta-Cell adaptation in a mouse model of glucocorticoidinduced metabolic syndrome. J Endocrinol 2013, 219:231-241

50. Friedline RH, Ko HJ, Jung DY, Lee Y, Bortell R, Dagdeviren S, Patel PR, Hu X, Inashima K, Kearns C, Tsitsilianos N, Shafiq U, Shultz LD, Lee KW, Greiner DL, Kim JK: Genetic ablation of lymphocytes and cytokine signaling in nonobese diabetic mice prevents diet-induced obesity and insulin resistance. FASEB J 2016, 30: $1328-1338$

51. Frazier B, Hsiao CW, Deuster P, Poth M: African Americans and Caucasian Americans: differences in glucocorticoid-induced insulin resistance. Horm Metab Res 2010, 42:887-891

52. van Rossum EF, Lamberts SW: Polymorphisms in the glucocorticoid receptor gene and their associations with metabolic parameters and body composition. Recent Prog Horm Res 2004, 59: 333-357

53. Baggiolini M: Chemokines and leukocyte traffic. Nature 1998, 392: $565-568$

54. Arima Y, Harada M, Kamimura D, Park JH, Kawano F, Yull FE, Kawamoto T, Iwakura Y, Betz UA, Marquez G, Blackwell TS, Ohira Y, Hirano T, Murakami M: Regional neural activation defines a gateway for autoreactive $\mathrm{T}$ cells to cross the blood-brain barrier. Cell 2012, 148:447-457
55. Schutyser E, Struyf S, Van Damme J: The CC chemokine CCL20 and its receptor CCR6. Cytokine Growth Factor Rev 2003, 14: 409-426

56. Carr MW, Roth SJ, Luther E, Rose SS, Springer TA: Monocyte chemoattractant protein 1 acts as a T-lymphocyte chemoattractant. Proc Natl Acad Sci U S A 1994, 91:3652-3656

57. Calderon B, Suri A, Unanue ER: In CD4+ T-cell-induced diabetes, macrophages are the final effector cells that mediate islet beta-cell killing: studies from an acute model. Am J Pathol 2006, 169: 2137-2147

58. Medicherla S, Protter AA, Ma JY, Mangadu R, Almirez R, Koppelman B, Kerr I, Navas TA, Movius F, Reddy M, Liu YW, Luedtke G, Perumattam J, Mavunkel B, Dugar S, Schreiner GF: Preventive and therapeutic potential of p38 alpha-selective mitogenactivated protein kinase inhibitor in nonobese diabetic mice with type 1 diabetes. J Pharmacol Exp Ther 2006, 318:99-107

59. Burke SJ, Goff MR, Updegraff BL, Lu D, Brown PL, Minkin SC Jr, Biggerstaff JP, Zhao L, Karlstad MD, Collier JJ: Regulation of the CCL2 gene in pancreatic beta-cells by IL-1beta and glucocorticoids: role of MKP-1. PLoS One 2012, 7:e46986

60. Weinstein DS, Gong H, Doweyko AM, Cunningham M, Habte S, Wang JH, Holloway DA, Burke C, Gao L, Guarino V, Carman J, Somerville JE, Shuster D, Salter-Cid L, Dodd JH, Nadler SG, Barrish JC: Azaxanthene based selective glucocorticoid receptor modulators: design, synthesis, and pharmacological evaluation of (S)-4-(5-(1-((1,3,4-thiadiazol-2-yl)amino)-2-methyl-1-oxopropan-2-yl)5H-chromeno[2,3-b]pyridin-2-yl)-2-fluoro-N,N-dimethylbenzamide (BMS-776532) and its methylene homologue (BMS-791826). J Med Chem 2011, 54:7318-7333

61. Yates CM, Brown PJ, Stewart EL, Patten C, Austin RJ, Holt JA, Maglich JM, Angell DC, Sasse RZ, Taylor SJ, Uings IJ, Trump RP: Structure guided design of 5-arylindazole glucocorticoid receptor agonists and antagonists. J Med Chem 2010, 53:4531-4544

62. Burke SJ, May AL, Noland RC, Lu D, Brissova M, Powers AC, Sherrill EM, Karlstad MD, Campagna SR, Stephens JM, Collier JJ: Thiobenzothiazole-modified hydrocortisones display anti-inflammatory activity with reduced impact on islet beta-cell function. J Biol Chem 2015, 290:13401-13416

63. Atkinson MA, Maclaren NK, Luchetta R: Insulitis and diabetes in NOD mice reduced by prophylactic insulin therapy. Diabetes 1990, 39:933-937

64. Gotfredsen CF, Buschard K, Frandsen EK: Reduction of diabetes incidence of BB Wistar rats by early prophylactic insulin treatment of diabetes-prone animals. Diabetologia 1985, 28:933-935 